\title{
Los mártires de América Latina, a la luz del martirio de Perpetua y Felícitas
}

\author{
Elsa Tamez, \\ San José, Costa Rica.
}

\section{Breve genealogía del martirio de nuestros días}

El evangelio de Mateo comienza con una genealogía de Jesús: "Libro de los orígenes de Jesús, hijo de David, hijo de Abraham. Abraham engendró a Isaac, Isaac engendró a Jacob...". El autor quiere identificar quién es ese Jesús, que también lleva por nombre Emmanuel, "Dios con nosotros", porque se empeña en vivir entre los humanos aun después de su muerte.

$\mathrm{Al}$ igual que Mateo, quiero iniciar mi exposición con una genealogía simbólica, porque creo que también hay una genealogía del martirio. Creo que hay un puente que une el primer martirio de los cristianos, el martirio de Jesús, con los martirios de hoy. Se trata de los descendientes "espirituales" de Jesús, martirizados como él. Su identidad es de cristianos, seguidores de Jesús; su memoria es la memoria de los mártires. También, como Jesús, estos mártires se empeñan en vivir entre los humanos, aun después de su muerte, para animarnos e iluminarnos, como Monseñor Romero. Por eso, su vida y muerte pueden ser evangelio, es decir, buena noticia, como la nube de testigos mencionada, en la carta a los Hebreos.

Quiero comenzar "el evangelio de mujeres y hombres mártires", con una "genealogía" - muy limitada por cierto- de descendientes de Jesús, por la línea del martirio. Se trata de una genealogía correspondiente al mes de marzo. Evocarlos es hacerlos presente, en este veinticinco aniversario del martirio de Monseñor Romero, asesinado también en marzo de 1980.

Argentina: Joaquín Carregal, Remigio Morel, Pedro Medina y Daniel de la Sierra, sacerdotes de la diócesis de Quilmas. Todos asesinados los 7 de marzo de los años 1992 - 1994. Nelio Rougier, sacerdote religioso de Foucauld, 15 de 
marzo de 1975. Antonio Olio y Pantaleón Romero, campesinos de Perugorría, 16 de marzo.

Bolivia: Luis Espinal, sacerdote, 22 de marzo de 1980 (también este mes cumple veinticinco años, como Monseñor Romero).

Chile: muchos nombres murieron todos los 14 de marzo, de los años de 1973 a 1994. Eduardo Rafael y Pablo Vergara Toledo, asesinados los 29 de marzo de los años 1985-1988.

Colombia: María Gómez, maestra catequista del pueblo Simití, 26 de marzo de 1989.

Guatemala: Antonio Chaj, pastor, y Manuel de Jesús Recinos, ambos de la Iglesia evangélica, no se sabe qué día de marzo de 1977. María Mejía, campesina solidaria de Parraxtut, 17 de marzo de 1990.

México: Luz Marina Valencia, religiosa, luchadora a favor de los campesinos, 21 de marzo de 1987. Rafael Hernández, luchador a favor de los campesinos, 22 de marzo de 1988.

Nicaragua: María Mejía, campesina, y Presentación Ponce, delegado de la Palabra, 18 de marzo de 1981. Donato Mendoza, delegado de la Palabra, 25 de marzo de 1986.

El Salvador: Rutilio Grande, sacerdote; Menche Ruiz, catequista, Manuel y Nelson, campesinos, 12 de marzo de 1977; Monseñor Oscar Arnulfo Romero, a quien hoy recordamos en su veinticinco aniversario, asesinado el 24 de marzo de 1980.

He mencionado algunos mártires, mujeres y hombres desde 1973. Hay muchísimos más mártires de marzo, antes y después de esa fecha. Escogí estos nombres al azar, porque tuvieron la suerte de ser recogidos en algún libro escrito ${ }^{1}$. Quise empezar mencionando nombres, porque todas las personas tenemos nombre. El ser humano no es un número. A veces, tenemos que dar estadísticas: 96 millones de personas viven en la pobreza extrema en América Latina, por ejemplo, o el desempleo en tal país es de 40 por ciento, o asesinaron a diez personas de los sin tierra.

El libro Guatemala: nunca más, por ejemplo, registró 422 masacres², la mayoría en la zona del Quiché. Este número, que se refiere al "pueblo crucificado", como los llamaba Ellacuría, nos espanta; pero es justamente por eso que también

1. Estos nombres aparecen en el libro Profetas para un mundo nuevo. Memoria de martirio en América Latina, organizado por María Bertha Arroyo, México, 1996.

2. Arzobispado de Guatemala, Oficina de derechos humanos, Guatemala: nunca más, Guatemala, 1998, Vol. II. 
es bueno conocer las estadísticas. Con ello, discernimos mejor la densidad de las tinieblas, la irracionalidad del pecado. Sin embargo, detrás de las estadísticas debemos contemplar, de cerca, el drama de cada una de las vidas asesinadas; recordar que tienen nombre, historia, y sueños compartidos. Recordar que no son números, sino personas con cuerpos de mujer o de hombre, de niños, jóvenes o ancianos, de diferentes culturas, razas, iglesias y hasta de clases sociales. Recordar que cada uno de ellos representa un profundo sufrimiento para su familia, sus amigos y su comunidad. Recordar que cada uno sufrió en su piel y entrañas la tortura de diferente modo.

\section{Perpetua y Felícitas}

En honor a la vida concreta de los mártires, voy a retomar el martirio de Perpetua y Felícitas, dos mujeres mártires del año 202 o 203 de nuestra era, arrestadas también en el mes de marzo, un día 7 u 8, durante la persecución del emperador romano Severo, por no ofrecerle culto. Ellas pertenecen a la genealogía de marzo; forman parte del puente de martirios, que une el martirio de Jesús con los martirios de hoy. Quisiera que viéramos algunos detalles de "la última hora", sus pensamientos y sueños, su fortaleza y temor, su ejemplaridad.

Mi objetivo no es quedarnos en sus historias personales pasadas, sino, al contrario, mi intención es que veamos, a través de la vida de esas mujeres, la experiencia particular de todos los mártires de América Latina, mujeres y hombres, que dieron su vida por la causa del reino de Dios. Asimismo, mi intención es que percibamos en sus vidas la proclamación de un evangelio que remite, sin duda, al evangelio de Jesucristo. He escogido cuatro aspectos del relato del martirio de Perpetua y Felícitas para meditar sobre los mártires de América Latina: los cuerpos, la familia, la sociedad enemiga y, por último, Dios y la comunidad amiga.

\subsection{Los cuerpos}

Los mártires no son almas libres de cuerpos. Son vidas con cuerpos, que sufren el maltrato, el abuso, la humillación, la tortura o el hambre. No hay testimonios de mártires en América Latina, ni en el mundo, que no se refieran a esa dimensión corporal. El relato de Perpetua y Felícitas está lleno de esta experiencia.

Perpetua es una mujer libre, de unos veintidós años, recién bautizada, casada, tiene un hijo de meses. Felícitas es una mujer esclava, ingresa en prisión embarazada de ocho meses. En su testimonio Perpetua se expresa libremente sobre su cuerpo. Ella logró un permiso para poder amamantarlo en la cárcel, "el niño estaba muerto de hambre", dice. Su preocupación y ansiedad por el bebé eran grandes. El niño fue entregado a la madre de Perpetua para su cuidado. Más tarde, Perpetua se dio cuenta que el niño se había acostumbrado a ser amamantado y a estar con ella en la prisión. De manera que mandó pedir que se lo trajeran de nuevo, pero el padre se negó a dárselo. Frente a este detalle, sin aparente significado, Perpe- 
tua dice: "pero fue la voluntad de Dios que el niño no deseara más mamar del pecho, ni que yo sufriera inflamación en el pecho, de esa manera fui liberada de la ansiedad por mi hijo y de las molestias de mis pechos".

Felícitas da a luz en la prisión. Ella y Perpetua, junto con otros cuatro varones: el esclavo Revocatus, Saturninus, Secundulus y Saturus, habían sido condenados a ser comidos por las bestias en el anfiteatro. Pero Felícitas, la esclava, estaba preocupada porque, de acuerdo a la ley, su ejecución tendría que ser pospuesta por estar embarazada. Y en verdad, no era lo mismo sufrir el martirio acompañada de los otros hermanos que sola y desamparada. Por eso, todos ven como acción de Dios que el embarazo se adelante y dé a luz en la cárcel a su hija, a los ocho meses. El relato dice que los dolores de parto eran inmensos, por ser de ocho meses.

Para nosotros, en América Latina, no es difícil cambiarle el nombre a Perpetua: Lupita, María, Lola... Este relato antiguo, nos ilumina las cárceles oscuras de hoy, donde tantas mujeres han dado pecho a sus hijos o han dado a luz. Comparado con lo que hoy ocurre, Perpetua y Felícitas tuvieron suerte, pues sus hijos quedaron vivos y fueron entregados a familiares, mientras que muchas de nuestras mujeres mártires no alcanzan ni a saber si su hijo fue niña o niño. Se los arrancaron de su vientre o para matarlos o para darlos a terceros. Marta Gonzáles de Baronetto, casada, madre de dos hijos, embarazada de cuatro meses, miembro de las comunidades cristianas de formación bíblica, es detenida en Argentina, por la policía. A los nueve meses de embarazo, da a luz, en la cárcel, con las manos esposadas. Su mayor dolor es no poder amamantar a su hijo, Lucas Ariel. Dos meses después de dar a luz, es fusilada, el 11 de octubre de 1976.

Los varones también sufren en su cuerpo los abusos en el cuerpo de cada miembro de su familia. Son muchos los mártires varones que han sufrido la humillación de ver a sus hijas o hijos desnudos, ser violados y torturados delante de ellos como escarmiento. En la tumba de Marta se lee un texto del profeta Isaías: "Tus muertos revivirán y en el país de las sombras darás Luz"3.

\subsection{La familia}

La familia forma parte de lo cotidiano; todos o casi todos los mártires tienen que enfrentarlo de alguna forma. La fortaleza de Perpetua es admirable con respecto a los suyos. Ella tiene que soportar la presión de su familia, sobre todo la de su padre. Por un lado, tiene el apoyo de su madre y su hermano, pero por otro, tiene la oposición del padre, quien por no ser cristiano, no entiende ese empecinamiento de Perpetua de no ofrecer culto al emperador. Cuatro veces la visita en la cárcel, para presionarla y hacer que rinda culto al emperador y no sufra el martirio.

3. María Berta Arroyo, Profetas para un mundo nuevo, 1996, pp. 330s. 
La primera, furioso, con "ganas de sacarle los ojos". Cuando se fue, Perpetua dijo: "Fui confortada por su ausencia". La segunda visita es para implorarle que tenga piedad de él, de su cabeza gris, de la familia, de su honor pues, si ella es condenada, no podrá hablar con libertad en la sociedad. Los va a destruir a todos, dice el padre. Ahora se muestra tierno: le besa las manos, se tira al suelo, y, llorando, ya no se dirige a ella como a la hija de un paterfamilias, sino como una mujer, una señora. La tercera vez, antes de ir a la audiencia, el padre llega de nuevo, ahora con el hijo en los brazos, y le insiste: "Ofrece el sacrificio [al emperador], ten piedad de tu hijo". El gobernador, que observaba cerca, también presiona, pidiéndole piedad por su padre de canas y por su hijo. También le pide que ofrezca el sacrificio por el bienestar del emperador. Ella continúa resistiendo: "No ofreceré". "¿Eres cristiana?", le pregunta el gobernador, "Sí, soy cristiana”, responde Perpetua. Y el gobernador manda azotar al padre delante de ella. "Yo me sentí muy mal por mi padre, dice Perpetua. Sentí como si a mí me estuvieran golpeando".

Una última vez llega el padre, se arranca los pelos de la barba y los tira al piso; después, él se tira al piso también y empieza a maldecir su vejez, derrotado, impotente. Perpetua se sintió muy triste, por la infelicidad de su padre. Sin embargo, trata de confortarlo. Dice en su diario: "Yo traté de confortarlo, diciendo: 'Todo pasará como Dios quiere; tu puedes estar seguro de que nosotros no somos abandonados a nosotros mismos, sino que estamos todos en su poder"'.

Felícitas no tiene familia, porque es esclava. No tiene el consuelo de una madre o hermanos, como Perpetua. Sin embargo, tiene una familia que la acompaña, son los demás creyentes, condenados también a muerte. Yo estoy segura que en la mente de ustedes corren muchos nombres de mártires con una experiencia semejante con respecto a la familia.

Innumerables son los testimonios alrededor de las familias de los mártires de estos días. Hoy, quiero traer la memoria a un padre de familia chileno. Su hija Candelaria, madre de dos niños, fue sacada de su casa a la fuerza. Su hijo Galo había sido detenido el día anterior, 9 de noviembre de 1983. Los responsables de la detención fueron los de la CNI, Central Nacional de Informaciones. Los jóvenes eran acusados de terroristas. Todos sabían que era una infamia. El padre buscó por todos los medios desmentir la acusación, pero fue imposible. Don Tan, como le decían, el viernes 11 de noviembre, pensando en las torturas que sufrían sus hijos injustamente, decide sentarse frente a la catedral de Concepción, rociarse con bencina y prenderse fuego. Gritaba: "iQuiero que la CNI

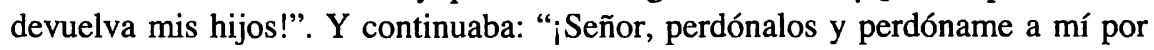
este sacrificio! Un sacerdote se acercó a él, convertido ya en una tea, para rezar con él y darle la absolución. Su hija Candelaria fue liberada en ese momento. Las últimas palabras de su padre fueron las siguientes: "Hija, lo hice por todos los padres del mundo que tienen hijos detenidos". Por esa acción, la Iglesia pide la abolición de la CNI. 
He aquí dos padres que sufren de distinta manera, el de Perpetua, y el de Candelaria, quien se convirtió en un mártir por los sufrimientos de todos los familiares de los mártires.

Nicolás Castro, conocido también como Nicolás Tum Quistán, un indígena de El Quiche, era ministro de la eucaristía. Llevaba la comunión escondida entre los frijoles y el maíz a lugares donde las parroquias estaban abiertas, ya que las parroquias de su diócesis estaban cerradas, para evitar más asesinatos de curas. Un día llegan a su casa y lo matan enfrente de su esposa, madre e hijos. Antes de morir les dice: "Oren a Dios porque van a sufrir mucho. No lloren por mí, porque voy a morir, pero voy a resucitar". Eso fue el 12 de noviembre de $1980^{4}$. Hoy, 28 de marzo del 2005 , lo traigo presente aquí, ante ustedes, como un resucitado.

\subsection{La sociedad enemiga}

Los cristianos perseguidos, en tiempos del imperio, durante los primeros siglos, eran odiados por la sociedad de su tiempo. Para Tácito, historiador del primer siglo, el cristianismo era una perniciosa superstición, pues los cristianos, según él, celebraban "cosas atroces y vergonzosas". Los cristianos eran odiados, porque se decía que eran ateos y odiaban al género humano. Cuando Nerón los culpó del incendio de Roma, fueron condenados. Tácito mismo narra la forma como eran asesinados, y escribe: "Añadióse la justicia que se hizo de éstos, la burla y escarnio con que se les daba la muerte. A unos vestían de pellejos de fieras, para que de esta manera los despedazasen los perros; a otros ponían en cruces; a otros echaban sobre grandes rimeros de leña, a los cuales, en faltando el día pegaban fuego para que, ardiendo con ellos, sirviesen de luminarias en las tinieblas de la noches". Tantos eran los suplicios que hasta Tácito reconoce que los cristianos, "aunque merecedores del último suplicio, movían con todo eso a compasión y lástima grande"s.

Perpetua y Felícitas, al igual que sus compañeros de martirio, sufrieron el maltrato en la cárcel y el escarnio de la gente. De acuerdo al relato, fueron tratados con una severidad extraordinaria, porque se infiltró una información necia de que ellos iban a evaporarse o espiritualizarse, por arte de magia. Perpetua reclamó los maltratos y consiguió que fuesen tratados más humanamente. Para burlarse de ellos, fueron forzados a vestirse con ropas especiales. Los hombres, como sacerdotes de Saturno, y las mujeres con vestidos de sacerdotisas de Ceres. Perpetua se rehusó, de tal modo que el tribuno militar accedió a no vestirlos así. Las multitudes del anfiteatro embravecidas, exigieron que fueran azotados frente a la línea de los gladiadores. Osos, leopardos y jabalíes atacaron a los varones Saturus, Revocatus, Saturninus y Secundulus, pero para Felícitas y Perpetua habían preparado un ani-

4. María Berta Arroyo, op. cit., p. 376.

5. Cornelio Tácito, Anales, Libro XV, 256, México, 1991. 
se paraban como que si yo fuera piedra, se paraban sobre mí, se paraban sobre mí. Cuando me soltaron, ya estaba muerto mi finado esposo, yo ya no podía ni caminar; fui a ver a mi esposo y yo tenía dormidos los pies, las manos"8.

Este acto de pisotear repetidas veces, pasar por encima de una persona es muy simbólico, no se ve otra cosa que el odio de una sociedad enferma, que quiere aniquilar a cualquier sospechoso de no pensar de acuerdo a la ideología de dominación. Muchos cristianos, catequistas o pastores evangélicos, experimentaron esa misma tortura, antes del martirio. Llevaban una práctica como la de Jesús. Creo, como Jon Sobrino, que ellos, tal vez no son mártires por confesar a Jesús, pero sí mártires por actuar como Jesús. Sobrino los llama mártires jesuánicos ${ }^{9}$.

El imperio greco-romano se ensañó contra los cristianos de forma cruel. Nuestras sociedades actuales se ensañan aun con más crueldad contra aquellas personas, hombres y mujeres, cristianos o no, que proclaman paz y justicia y anuncian la buena nueva de la posibilidad de otro mundo, que aspire a ser algo parecido a lo que Jesús llamó reino de Dios. Monseñor Romero dijo, en su homilía del 8 de octubre de 1978: "Hermanos, ¡Cuánta bondad, cuánta verdad, cuánto bien hay más allá de las fronteras cristianas! Respetemos esto, porque muchas veces nos creemos nosotros por estar en la Iglesia que somos lo mejor del mundo. ¡Quién sabe si aquí dentro de la Iglesia somos menos buenos, menos nobles, menos humanos que allí afuera!"10.

\subsection{Dios y la comunidad amiga}

Quiero terminar el último punto aludiendo a Dios y a la comunidad amiga como fuerzas que hacen posible soportar el martirio, y también quiero hacer mención de la fuerza y esperanza que proyectan los mártires.

Felícitas y Perpetua soportaron el martirio con valentía, por su gran fe en Dios y por el apoyo y acompañamiento entre los mismos mártires y la comunidad de amigos, que tenían la misma fe. Perpetua tiene dos visiones y en ellas siente la fuerza de Dios. En una de las visiones, cuando lucha con un egipcio que, según ella, simbolizaba el mal, su entrenador, un asistente de Dios, le dio la rama de la victoria, la besó y le dijo: "la paz sea contigo". Entonces, dice ella: "Yo comencé a caminar hacia la puerta de la vida." Así era llamada la puerta donde los gladiadores vencedores salían de la arena. Sin embargo, la frase puede ser ambigua; para un cristiano, la puerta de la vida podría ser también el camino que lleva a Dios.

Veamos a Felícitas, la esclava. Cuando ella dio a luz con tanto dolor, un asistente de los guardias de la prisión le dijo: “'Tu sufres mucho ahora, ¿qué harás

8. Arzobispado de Guatemala, Guatemala: nunca más, op. cit.,Vol. II, p. 49.

9. Jon Sobrino, "Nuestro mundo, crueldad y compasión", op. cit., p. 19.

10. Equipo Educación Maíz, Monseñor Romero, el pueblo es mi profeta. San Salvador, 1994, p. 149. 
cosas que pasan sólo las conocemos por testimonios orales de los más cercanos. Jon Sobrino, sobreviviente de la comunidad jesuita de este país, asesinada en . noviembre de 1989, tiene inolvidables recuerdos de sus hermanos; en sus escritos u oralmente, nos cuenta de su fuerza, apoyo y valentía. El obispo metodista, Mortimer Arias, sobreviviente de la dictadura boliviana, apresado el 26 de agosto de 1980 , junto con otros cristianos comprometidos, cuenta a sus amigos cómo, cuando estaban juntos en una celda pequeña, viviendo la incertidumbre del día siguiente, experimentaron la fuerte presencia de Dios y cómo se fortalecieron mutuamente, compartiendo el mate entre todos. Era, dice, "como compartir la última cena". Escuchar eso, nos da fortaleza y esperanza, aun en tiempos de crisis y desesperanza, porque, como dice el jesuita Juan Hernández Pico, no podemos olvidar que detrás del martirio está un asesinato".

Hoy, a los veinticinco años del martirio de monseñor Oscar Arnulfo Romero, evocamos sus gestos, su vida y sus palabras, todo aquello que fortaleció a muchos de los que dieron su vida por la causa de la justicia, como seguimiento de Jesús, y que nos sigue animando hasta hoy. El 16 de septiembre de 1979, Monseñor dijo: "Ningún cristiano debe sentirse solo en su caminar, ninguna familia tiene que sentirse desamparada, ningún pueblo debe ser pesimista, aún en medio de las crisis que parecen insolubles, como la de nuestro país. Dios está en medio de nosotros. Tengamos fe en esta verdad central de la sagrada revelación. Dios está presente, no duerme, está activo, observa, ayuda y a su tiempo actúa oportunamente. Por eso, la presencia de Dios despierta en el corazón la verdadera alegría: ¡Alegraos en el Señor! De nuevo os repito: ¡Alegraos porque Dios está cerca!"'12.

El evangelio de Mateo al inicio nos recuerda que Jesús es Emmanuel, "Dios con nosotros". Al final de su evangelio, lo recuerda el mismo Jesús diciendo: "Yo estoy con ustedes todos los días hasta el fin del mundo" (Mt 28, 20).

Que estas palabras de Jesús, así como las de monseñor Romero, sean nuestras palabras en este veinticinco aniversario de su martirio.

En ocasión del 25 aniversario del martirio de Monseñor Oscar Arnulfo Romero, UCA.

San Salvador, 28 de marzo de 2005.

11. Juan Hernández Pico, "La esperanza que nace del amor de los mártires", Concilium 299 (2003) 149ss.

12. Publicaciones pastorales del Arzobispado. Día a día con Monseñor Romero. Meditaciones para todo el año, San Salvador, 1999, p. 290. 